\title{
La administración de la infancia y la adolescencia hoy
}

\section{Etnografiando acciones estatales orientadas a la protección y vigilancia de niñas, niños y adolescentes}

Florencia Graziano ${ }^{1}$ y Julieta Grinberg ${ }^{2}$

\author{
1 Programa de Antropología Política y Jurídica, Instituto de Ciencias Antropológicas, Facultad \\ de Filosofía y Letras, Universidad de Buenos Aires. \\ Consejo Nacional de Investigaciones Científicas y Tecnológicas. \\ (iD) https://orcid.org/oooo-0001-5525-7477 \\ Correo electrónico: grazianoflorencia@gmail.com
}

2 Programa de Antropología Política y Jurídica, Instituto de Ciencias Antropológicas, Facultad de Filosofía y Letras, Universidad de Buenos Aires.

Instituto de Estudios Sociales en Contextos de Desigualdades, Universidad Nacional de José C. Paz.

(iD) https://orcid.org/o0oo-0001-9788-2895

Correo electrónico: julietagrinberg@gmail.com doi: $10.34096 /$ cas.i53.8629
El presente dossier reúne investigaciones etnográficas relativas a las políticas públicas orientadas a la protección y vigilancia de los niños, niñas y adolescentes, provenientes de distintas latitudes. La propuesta apunta a profundizar y fortalecer una mirada analítica que contemple a las instituciones formalmente destinadas a la promoción y protección de derechos de niñas y niños y a aquellas orientadas al tratamiento de adolescentes acusados de cometer delitos como parte de un mismo campo institucional; esto es, como parte de un continuum de intervenciones destinadas a modelar, encauzar y transformar comportamientos y modos de ser, a partir de ayudar, apoyar, proteger, o bien, sancionar.

Durante las últimas dos décadas, este campo de estudios se ha alimentado de una prolifera y renovada producción académica capaz de combinar nuevos enfoques teóricos sobre el Estado y las políticas públicas con nuevos abordajes metodológicos. Los trabajos aquí reunidos se inscriben en una línea de indagación antropológica (Trouillot, 2001; Abrams, 2006; Sharma y Gupta, 2006; Das y Poole, 2008) que problematiza la idea de un Estado ahistórico y por fuera de entramados y transformaciones sociales, políticas y económicas, nacionales e internacionales. Discute la visión de un Estado coherente, homogéneo y armónico, ajeno a las tensiones y contradicciones entre la multiplicad de burocracias que lo componen y los actores que lo conforman y hacen de él un campo de disputas. A su vez, esta línea de investigación desarma la idea de una acción estatal circunscrita, con una direccionalidad única, y en tal sentido, concebida exclusivamente como una instancia de erogación de control y vigilancia. Ello a partir de documentar el repertorio variado de acciones a través de las cuales hoy se administran y regulan las infancias, las adolescencias y las familias, particularmente aquellas atravesadas por la
Nota de las autoras: queremos agradecer a todo el equipo editorial de la revista, comenzando por Virginia Manzano y Cecilia Benedetti, que se entusiasmaron cuando les propusimos este dossier y nos apoyaron durante el proceso. También a Mariana García Palacios y a Julieta Infantino por el acompañamiento a lo largo de todo el arduo trabajo editorial que implica la publicación de un dossier. A los investigadores e investigadoras que enviaron sus artículos a nuestra convocatoria y que por cuestiones de espacio no pudimos incluir. Por supuesto, a las autoras y a los autores, y las evaluadoras y evaluadores por toda su dedicación en estos momentos en los que el tiempo no abunda. Y finalmente, $a$ nuestra querida Carla Villalta por el apoyo y la generosidad de siempre. 
pobreza y la desigualdad social (Llobet, 2010; Lugones, 2012; Villalta 2013; Santillán, 2013; Ciordia, 2014; Barna, 2015; Magistris, 2016; Graziano 2017; Grinberg, 2017; Medan, 2017; Rojas Novoa, 2017; Medina, 2019).

Esta perspectiva construida a partir de diferentes indagaciones socioantropológicas resulta fundamental para tomar distancia de un enfoque legalista y tecnicista tendiente a interpretar las políticas públicas como meros reflejos de la aplicación mecánica de las normas y, por ende, como adecuadas o inadecuadas a lo que estas plantean. Esta clave de lectura ha estado muy presente en el campo de estudios de las intervenciones estatales sobre las infancias y adolescencias tanto en nuestro país como en la región. En nuestro contexto, la sanción de leyes y la implementación de políticas basadas en lo que en este campo de intervenciones se ha denominado como el enfoque de la "protección integral de derechos" ha estado atravesada por una visión abstracta y descontextualizada acerca de los derechos del niño (Fonseca y Cardarello, 2005).

Quien nos hace el honor de inaugurar el dossier con un artículo invitado que da cuenta de cómo esta perspectiva analítica sobre las intervenciones estatales hacia los/as niños/ as, adolescentes y sus familias ha proliferado en nuestro contexto local en el marco de discusiones tramadas desde la antropología política y jurídica, y en diálogo con otras ramas de la antropología y otras disciplinas, es Carla Villalta, reconocida por su trayectoria en este campo de estudios en el país y en la región. Su investigación sobre las prácticas de circulación, secuestro y apropiación de niños/as durante la última dictadura militar argentina ha puesto en evidencia las condiciones de posibilidad que habilitaron esas prácticas criminales. Nos ha mostrado la potencia de combinar la perspectiva sociohistórica con el abordaje etnográfico, al señalar cómo la existencia previa de nociones y sentidos, procedimientos y rutinas, relaciones y mecanismos de poder del campo de la minoridad sirvieron como punto de anclaje para el desarrollo de las mencionadas prácticas.

Hace más de una década que Carla Villalta ha fundado el equipo de investigación del que formamos parte: "Burocracias, derechos, parentesco e infancia", alojado en el Programa de Antropología Política y Jurídica del Instituto de Ciencias Antropológicas de la Facultad de Filosofía y Letras de la Universidad de Buenos Aires. Espacio a partir del cual se ha generado y expandido una línea de investigación orientada al análisis y reflexión sobre los dispositivos jurídico-burocráticos destinados a la administración de las infancias, adolescencias y familias signadas por la pobreza y la desigualdad, y sobre los circuitos institucionales, matrices interpretativas, saberes y técnicas que los componen.

El artículo que nos acerca realiza un aporte sustancial al campo de estudios de la administración estatal sobre la infancia, la adolescencia y sus familias, al reseñar de forma original diferentes investigaciones que, desde nuestra disciplina, han indagado sobre la cotidianeidad de las burocracias estatales. Rastrea cuatro construcciones analíticas a partir de las cuales las etnografías sobre estas temáticas realizadas en el país y en la región durante los últimos años conceptualizan algunas de las regularidades más persistentes en las dinámicas de intervención de este campo institucional: familiarización, maternalización, individualización y psicologización. Se trata de rasgos que predominan en las acciones que se desarrollan en estas instituciones, de matrices interpretativas a partir de las cuales se definen situaciones y se toman decisiones.

A lo largo del texto, describe las diferentes categorías y premisas que, desde distintos saberes, se han disputado sentidos diversos en torno a la infancia y la familia y cómo se han instalado nociones con pretensión de homogeneidad. Ideas de incompletitud, maleabilidad o indefensión han jugado un papel central en la conformación de determinadas claves de lectura acerca de lo que significa ser niño/a. En relación con estas 
ideas, Villalta examina el proceso de construcción de la familia moderna y los consecuentes mecanismos y procedimientos puestos en juego para moralizar y normalizar a las familias; procesos que han incidido en la familiarización del cuidado, la maternalización de las mujeres y, al mismo tiempo, en la familiarización de los "problemas sociales". Estas dinámicas se conjugan de manera complementaria con la emergencia de paradigmas interpretativos basados en un saber psi; una perspectiva muy presente en las intervenciones de este campo institucional que contribuye a individualizar y despolitizar problemas sociales.

De esta manera, a partir de una rigurosa exploración de las contribuciones de los últimos años, Villalta nos ofrece una síntesis conceptual de las principales coordenadas que han orientado las interpretaciones $y$, por lo tanto, reordenado las intervenciones en este campo institucional. Intervenciones que conjugan de manera tensa y a veces contradictoria lo ideal y lo posible, la ayuda y el control, los derechos y la moral. El artículo se vuelve así un imprescindible estado de la cuestión de la literatura sobre este campo de estudios en nuestro país y en la región.

El segundo artículo invitado para integrar este dossier es de Isabelle Coutant, socióloga francesa e investigadora cuyos estudios intersectan, desde una perspectiva etnográfica y con gran agudeza, temas vinculados con las clases populares, lo urbano, la juventud, la desviación y la inmigración. En sus investigaciones se ha interesado por las relaciones que las clases populares mantienen con instituciones como la justicia, el trabajo social y la psiquiatría cruzando el punto de vista de los profesionales con el del público atendido. Particularmente, ha abordado las políticas e intervenciones destinadas al tratamiento de la delincuencia juvenil en los barrios populares de la región parisina durante los primeros años de la década de 2000.

Para dar a conocer sus reflexiones, en este dossier presentamos un artículo publicado originariamente en francés en el libro Économies morales contemporaines, dirigido por Didier Fassin y Jean-Sébastien Eideliman (2012). Tomar conocimiento de los procesos sociohistóricos, de las lógicas y prácticas institucionales que atraviesan las intervenciones hacia las infancias y adolescencias en otros países resulta iluminador para poner en perspectiva los procesos locales de construcción del Estado y sus políticas. No solo porque permite dar cuenta de tematizaciones comunes a una época, de la circulación de teorías y problemas entre el ámbito global y el local, sino también porque posibilita poner en evidencia los procesos de apropiación y elaboración localmente situados.

En su artículo, pone la lente sobre la economía moral de la delincuencia juvenil desde una perspectiva analítica que articula el registro sociohistórico de las transformaciones relacionadas con su tratamiento entre 1945 y 1990 y la indagación etnográfica de las intervenciones e interacciones cotidianas que tienen lugar en el marco de una institución destinada al tratamiento de delitos de poca gravedad durante la década de 2000.

La autora remite a las transformaciones socioeconómicas durante la segunda mitad del siglo XX, a la desestructuración del mercado de trabajo hacia la década del setenta y a la consecuente precarización de las clases populares, factores todos estos que conducen a la emergencia de una nueva construcción alrededor de los jóvenes que el mercado laboral no logra integrar. El punto clave de este proceso se sitúa en la década del noventa, cuando la creciente preocupación por las víctimas y por la sensación de inseguridad se traduce en una menor tolerancia hacia el delito juvenil.

Se crean entonces las Maison de Justice, se trata de dispositivos judiciales territoriales, menos formales que el tribunal, cuya intervención se limita a delitos menores. Como propone la autora, las audiencias para adolescentes que allí se realizan pueden comprenderse como una forma de traducción de la economía moral sobre la delincuencia juvenil 
"en actos". Por un lado, porque permiten aprehender la confrontación entre sistemas de valores diversos representados por distintos actores. Por otro, porque posibilitan estudiar la diversidad de estrategias que los agentes institucionales despliegan para intentar "transformar" a los adolescentes a partir de activar en ellos sentimientos de miedo, culpa o vergüenza. Pero también porque permite identificar las tensiones y dilemas que los propios agentes institucionales vivencian en el marco de tales interacciones.

Los trabajos que tenemos el gusto de presentar en este dossier son producto de investigaciones finalizadas o en curso que promueven una mirada compleja del Estado y las políticas públicas orientadas a la protección y vigilancia de los niños, niñas y adolescentes en Argentina, Brasil y México. En ellos es posible identificar dos ejes conceptuales que los atraviesan y que dan cuenta de las discusiones presentes en este campo de estudios en constante expansión. El primero de ellos refiere a los procesos globales de elaboración de determinados problemas relacionados con la infancia, sus necesidades y derechos, y a las formas en que esos problemas circulan hacia los ámbitos nacionales. Ámbitos en los que, en función de las preocupaciones e intereses locales, son reelaborados y movilizados de formas diversas. El segundo eje gira en torno a la construcción de dichas políticas a partir de documentar la cotidianeidad de las burocracias administrativas y judiciales que las implementan y las interacciones puntuales y contextuales sobre las que se trama, en la actualidad, la acción estatal.

\section{Problemas, necesidades y derechos: entre lo global y lo local}

Diversos han sido los aportes que en nuestro campo de estudios han permitido reflexionar sobre los procesos de producción, circulación y reelaboración de conceptos y postulados de derechos humanos desde el plano internacional hacia los ámbitos locales. Queremos destacar los que, desde la antropología del derecho, realiza Sally Engle Merry $(2006,2009)$, quien ha señalado particularmente el rol de los intermediarios o traductores; activistas, profesionales y académicos que adaptan las ideas transnacionales a los términos locales y, al mismo tiempo, decodifican los problemas y reclamos propios de estos ámbitos al lenguaje de los derechos humanos producido a escala internacional. Esta clave de lectura permite reflexionar no solo sobre los modos en los que los derechos del niño han sido recepcionados y reelaborados en nuestro contexto nacional y regional, sino también sobre las formas en las que son adaptados a los significados locales, en función de culturas institucionales y lógicas burocráticas de larga duración (Llobet, 2009; Barna, 2012; Grinberg, 2013; Villalta, 2013, 2019). Además, estos trabajos han posibilitado documentar las interpretaciones y usos particulares que agentes institucionales con trayectorias diversas despliegan en el marco de sus intervenciones cotidianas con niños/as, adolescentes y familias. En tal sentido, la formulación de Claudia Fonseca y Andrea Cardarello (2005) respecto de que los derechos humanos carecen de significación por fuera de contextos específicos ha sido señera en este campo de estudios. En otras palabras, ha permitido comprender que los derechos humanos no portan un contenido universal y ahistórico, sino que adquieren significados y existencia en la práctica diaria y a partir de su imbricación con las condiciones derivadas de determinados contextos sociales y políticos.

Parte de los trabajos reunidos en este dossier abonan estas discusiones al abordar las relaciones complejas entre los ámbitos nacionales e internacionales. Permiten visibilizar cómo determinadas ideas e imágenes de infancia, problemas y categorías de intervención o discursos y narrativas producidos a escala global circulan hacia los ámbitos locales por medio de diversas vías; por ejemplo, a partir de la producción de conocimientos, saberes e ideas, de la construcción de líneas de financiación internacional específicas y de la creación de normativas vinculadas a los derechos del niño que son diferencialmente recepcionadas en los distintos contextos nacionales. Los trabajos 
de Fernanda Bittencourt Ribeiro, Irene Pochetti y Florencia Paz Landeira analizan el rol de los organismos regionales e internacionales en la construcción y divulgación de categorías de intervención pública. La "infancia desamparada" hacia fines de los setenta, "el niño de la calle" entre los ochenta y los noventa, y la "primera infancia" en la actualidad, son abordadas respectivamente por dichas autoras. Mientras que el trabajo de Bittencourt Ribeiro hace foco sobre la construcción a nivel regional de una idea de infancia latinoamericana, los trabajos de Pochetti y Paz Landeira avanzan sobre la circulación de categorías y narrativas en México y Argentina. De este modo, además de señalar los movimientos y flujos externos, estas últimas autoras problematizan los procesos de recepción y reelaboración local, complejos y contradictorios, que tienen lugar en contextos específicos. Señalan así el rol activo de los actores intermediarios e identifican la pluralidad de interpretaciones y usos en torno a esas categorías y discursos.

El artículo de Fernanda Bittencourt Ribeiro se interesa por la construcción de imágenes de infancia hacia fines de la década del setenta en América Latina. A partir de articular un análisis de documentos y de cuadros expuestos en la Galería de Niños de América del Instituto Interamericano del Niño (IIN), el artículo explora la imagen de la infancia latinoamericana diseñada y promovida desde este organismo dependiente de la OEA. Los boletines difundidos en la época le sirven a la autora para reconstruir la historicidad y politicidad que encierran estos retratos "representativos" de niños de los diferentes países.

La autora analiza la galería como una producción simbólica que participó de la construcción de una infancia interamericana con características particulares y sobre la cual se vuelve preciso intervenir: la "infancia desamparada" y portadora de futuro. Una niñez indefensa y a la vez digna y necesitada de protección. Se trata de una imagen que, si bien contrasta con aquella de la situación irregular promovida durante el siglo XX por el mismo IIN, también contribuye a invisibilizar el problema del "niño de la calle", reconocido entonces por diversos organismos internacionales. Se trata de una imagen que a su vez se aleja de aquella de la infancia universal que circulaba por entonces en el ámbito internacional y que una década más tarde se impone con la Convención sobre los Derechos del Niño (CDN). De este modo, el sistema simbólico que se activa desde el IIN incluye definiciones respecto de la importancia de sus acciones en el continente. Si bien visibiliza a "la niñez desamparada" como objeto de intervención y, por medio de ello se legitima, al no hacer de esa niñez una víctima de las acciones y omisiones de los Estados, tampoco los responsabiliza. Pero si de omisiones se trata, como señala la autora, no es lo único que estas imágenes y discursos ocultan: ellos tampoco dicen de la situación política de la región.

El artículo de Irene Pochetti, por su parte, se interesa por el modo en que los discursos relativos a los derechos del niño y al género son apropiados y resignificados en México entre fines de los años noventa y comienzos de 2000. Ello a partir de explorar cómo ambos se imbrican en un campo de intervención específico como es la infancia en calle. Tal como repone la autora, la CDN fue ratificada en un contexto de renovación democrática y de ampliación de derechos individuales, que a la vez coincide con la implementación de políticas económicas de corte neoliberal. En este contexto, bajo el impulso de organismos no gubernamentales de carácter internacional, y particularmente a través de la creación de líneas específicas de financiamiento, se multiplican las organizaciones de la sociedad civil (OSC) abocadas a la atención de la infancia callejera. Paralelamente, emergen algunas especializadas en la atención de niñas en situación de calle.

En este campo de intervención, como analiza Pochetti, los derechos del niño y el género son objeto de usos diversos y ciertas veces contradictorios. En efecto, en su doble 
crítica al asistencialismo y a las políticas neoliberales, las organizaciones se oponen a la simple ayuda y, paradójicamente, promueven la responsabilidad individual a través de fomentar la voluntad y el compromiso de los niños/as. A su vez, la adopción de un lenguaje de derechos se imbrica con la difusión del enfoque de género, pero la incorporación de este último al campo de las instituciones estudiadas se hace desde un feminismo esencialista. Así, la autora reflexiona sobre el contexto de recepción y apropiación local de normas y categorías definidas en el plano internacional, y señala los movimientos externos y las dinámicas internas que se combinan en estos procesos complejos y contradictorios.

La producción y circulación desde el ámbito internacional hacia el campo local de construcción de problemas en torno a la infancia y de soluciones para hacer frente a ellos es también abordada en el trabajo de Florencia Paz Landeira. En este caso, el foco está puesto sobre las conceptualizaciones relativas al desarrollo de la primera infancia en Argentina, en su construcción como problema de agenda pública y en los usos que despliegan actores con trayectorias y posiciones diversas en un campo en proceso de institucionalización. Durante las últimas décadas, la primera infancia ha sido construida por parte de organismos internacionales como una etapa crucial para el desarrollo de los/as niños/as. Esta construcción, que se apoya en la teoría de la inversión social y el capital humano, se nutre de los aportes de las neurociencias en un contexto a su vez caracterizado por la internacionalización de los derechos del niño. Desde la combinación que resulta de estos discursos se postula la centralidad del desarrollo cognitivo durante los primeros años de vida y se promueve la intervención temprana en los procesos de crianza.

La autora destaca el rol de diversos actores involucrados/as en la producción de políticas hacia la primera infancia y visibiliza su rol de traductores, en tanto intérpretes de narrativas producidas en el plano transnacional hacia los ámbitos nacionales, en función de intereses y problemáticas localmente definidas. Muestra que ellos interpretan de modos diversos los discursos hegemónicos en torno a la primera infancia, realizan un uso político y estratégico de estos, y al hacerlo participan activamente de la producción de políticas públicas. En este marco, mientras que algunos utilizan dichas narrativas para generar consensos, otros despliegan usos estratégicos tendientes a captar financiamientos de agencias internacionales y otros ofrecen resistencias. Estas resistencias resultan inteligibles al analizar el contexto político de cambio de gestión y redefinición de los límites y alcances del Estado que enmarca el proceso en el que se desarrolla la investigación.

\section{La dimensión cotidiana de las burocracias administrativas y judi- ciales}

El segundo eje conceptual que hemos identificado como articulador del resto de los trabajos que integran el dossier remite a los procesos de construcción de políticas e intervenciones hacia las infancias, adolescencias y familias desde una perspectiva cotidiana, interaccional y territorializada. Ello a partir de reflexionar sobre el quehacer de las burocracias judiciales y administrativas y de analizar cómo se van modelando allí distintas clasificaciones, evaluaciones y prácticas que dan forma a la acción estatal. Se trata de procesos en los que tanto las relaciones entre diversos actores institucionales como aquellas interacciones cotidianas que se dan entre agentes estatales, niños/as, adolescentes y familias, redefinen y moldean los alcances y sentidos del Estado y de sus objetivos manifiestos de prevenir, proteger, encauzar y transformar.

Lejos de ser diseños cerrados que resultan de la aplicación mecánica y unívoca de las leyes, las políticas son el resultado de acciones de personas de carne y hueso, con 
trayectorias diversas, insertas en tramas de relaciones sociales y de tradiciones institucionales. En tal sentido, en lugar de ser una entidad monolítica con una direccionalidad única y lineal, una fuente de erogación de control y de vigilancia, el Estado es más bien un campo heterogéneo e incluso contradictorio; y es desde esas tensiones y disputas que se delimitan y construyen las formas que asume y los alcances que tiene hoy la intervención sobre la infancia pobre y sus familias (Villalta, 2010).

En efecto, como nos ha mostrado Michel Foucault (2007), el poder estatal no es absoluto, unidireccional, ilimitado, carente de fisuras; tampoco se despliega exclusivamente desde el Estado mismo, sino que lo hace también a partir de otras instancias con las que mantiene fronteras difusas (Das y Poole, 2008). Y por sobre todo, el ejercicio de poder -entendido como un conjunto de acciones sobre las acciones de los otros- no opera solo prohibiendo y haciendo uso de la fuerza y la coerción, sino también recurriendo a técnicas sutiles, flexibles y negociadas. Es así que, en las intervenciones destinadas a proteger y vigilar a niños/as, adolescentes y sus familias, actualmente predomina un registro pedagógico desde el cual se privilegia la palabra, los acuerdos y las relaciones de empatía entre administradores y administrados (Lugones, 2012; Barna, 2015; Grinberg, 2016; Graziano, 2017). Y a su vez, este registro es psicologizante, ya que apela a la participación de los individuos, a su responsabilidad y al compromiso como condiciones necesarias para lograr la propia reconversión subjetiva (Llobet, 2009; Grinberg, 2017; Graziano, 2020a). En estos procesos de regulación de la infancia, la adolescencia y la familia intervienen también las emociones, los sentimientos y los valores morales que orientan los discursos y las prácticas institucionales (Ciordia y Villalta, 2009; Vianna, 2010; Eilbaum, 2015; Coutant, 2012; Grinberg, 2012; Fassin, 2016; Graziano, 2017).

Los artículos aquí reunidos alimentan estas discusiones a partir de analizar las interacciones puntuales y contextuales que construyen el ejercicio concreto de la administración estatal. Algunos de ellos ponen el foco en la cotidianeidad de las burocracias del campo penal juvenil, que son punitivas y tutelares a la vez, y muchas veces también, estratégicas e intermediarias (Graziano, 2020b). Esto es, persiguen penalmente pero al mismo tiempo deben proteger y también ayudar a las personas en los intrincados caminos institucionales, como nos muestran los artículos de Federico Medina y Danielli Viera. Se trata de formas de administración que se orientan a modificar conductas y relaciones sociales, pero que no se basan exclusivamente en una mera imposición, sino que se trata de procesos que incluyen estrategias de negociación y de persuasión que apelan a emociones, sentimientos y valores particulares y que se expresan en términos de un lenguaje moral.

En los artículos mencionados y también en el de Natalia Larrea sobre servicios de protección de derechos, observamos cómo la impronta educadora o pedagógica -esto es, la transmisión de "buenas formas" (de ser, de actuar)- es una constante en el discurso y quehacer de los agentes estatales. Se trata de un trabajo de ayuda, de orientación, de acompañamiento, para que tanto los/as niños/as y adolescentes como los miembros de sus familias logren modificar sus comportamientos. Estas prácticas se observan también en el trabajo de Ranna Mirthes Sousa Correa sobre una oficina judicial abocada a persuadir sobre la importancia del reconocimiento de la filiación paterna. En este trabajo, al igual que en el de Danielli Vieira, se observa el análisis de las confrontaciones microscópicas de los sujetos administrados que resisten o contestan las acciones de los agentes estatales; a través de ello, estos trabajos iluminan las prácticas de los destinatarios de las intervenciones, y al hacerlo contribuyen a desarmar la idea de un poder estatal absoluto, ejercido sobre sujetos dóciles y pasivos.

Ranna Mirthes Sousa Correa realiza su etnografía en una oficina judicial creada para promover el reconocimiento espontáneo de la filiación paterna en el noreste de Brasil. A partir de la observación de la rutina de trabajo del juzgado, de las conversaciones 
mantenidas en la sala de espera y de las audiencias de conciliación (en las que se discute tanto el nuevo nombre de un/a niño/a, la convivencia y la cuota de alimentos, como la realización del examen de $\mathrm{ADN}$ ), Sousa Correa analiza las interacciones que se dan entre las profesionales (asistentes sociales y psicólogas) y las madres que son convocadas a fin de que entiendan la importancia del reconocimiento de la paternidad. Nos muestra el trabajo de sensibilización que allí se realiza, en el que la intuición, la confianza (o la desconfianza), las distintas nociones de verdad y ciertos valores morales se articulan y se tensionan entre las madres intimadas y las profesionales. Estas interacciones tienen lugar en una sala en la que se leen mensajes tales como "Sabio es el padre que reconoce al propio hijo" o "La paternidad responsable comienza por el registro", los cuales nos muestran que el mundo del derecho no es solo un simple ordenador legal de las relaciones sociales, sino también una arena de moralidades en disputa.

En orden de presentación le sigue el artículo de Natalia Larrea, quien busca comprender las modalidades que asume en la actualidad la protección de la infancia considerada "en riesgo". A partir de su etnografía, realizada en un dispositivo estatal de protección de derechos de la infancia en una localidad de la provincia de Buenos Aires, Larrea nos muestra las intervenciones concretas efectuadas por los agentes que allí trabajan y observa cómo esas prácticas -orientadas por un lenguaje de los derechos- se ven muchas veces tensionadas cuando deben traducirse y adecuarse a situaciones puntuales. $\mathrm{Al}$ analizar las contradicciones y dilemas surgidos en las prácticas reales que encarnan los derechos, su artículo nos ofrece valiosas pistas para comprender las dinámicas locales de intervención estatal sobre la infancia y sus familias.

En el marco de estas intervenciones, la familia se vuelve una clave interpretativa muy potente para explicar las conductas y comportamientos de los niños; una clave explicativa que, moldeada por categorías institucionales de clasificación de sujetos y conflictos, genera determinados registros de inteligibilidad y ayuda a la práctica diaria de los operadores en el manejo de las incertezas. A partir del análisis de las interacciones que tienen lugar entre las madres, padres y agentes estatales, señala cómo esas relaciones, en las que priman evaluaciones morales sobre los roles y comportamientos familiares, no están signadas por la mera imposición de formas "correctas" de ser y de hacer, sino que, apelando al diálogo, a la persuasión y a la empatía, se logran negociaciones y se construyen acuerdos.

Las interacciones constituyen también la materia prima del trabajo de Federico Medina. En su caso, entre jóvenes acusados de delitos y agentes judiciales de una oficina de Santiago del Estero dedicada a implementar medidas alternativas a la privación de libertad. El autor, además, analiza usos y sentidos diversos asociados a la implementación de estas medidas y, al iluminar la dimensión cotidiana de esa oficina judicial, da cuenta de las formas domésticas que la utilización de las llamadas medidas alternativas adquiere en el orden local. A partir de las microescenas que Medina nos trae, es posible observar y comprender cómo estas estrategias que se presentan como innovadoras en el tratamiento de la infracción juvenil son interpretadas y apropiadas por diferentes tipos de agentes, que les imprimen particulares sentidos y se inscriben en tradiciones institucionales y rutinas burocráticas existentes. A su vez, la etnografía resalta la dimensión performativa de la administración de justicia y muestra cómo unos y otros-administradores y administrados- actúan el juego del mundo judicial.

Finalmente, las instituciones del ámbito penal juvenil son también abordadas en el artículo de Danielli Vieira. Su trabajo se interesa por un dispositivo de semilibertad ubicado en la región sur de Brasil, donde se encuentran niñas/os y adolescentes cumpliendo "medidas socioeducativas" por haber sido acusados de realizar una infracción penal siendo menores de 18 años. La autora presta especial atención a sus narrativas cargadas de descripciones de violencias y malos tratos por parte de los agentes institucionales. 
Intentando ir más allá de la denuncia y la indignación que los relatos escuchados le generan, procura realizar una lectura analítica de las situaciones observadas. Ello a partir de comprender cómo las violencias son significadas por estos/as niños/as y adolescentes, y cómo esas experiencias generan resistencias e inciden sobre sus vidas, sus valores y sobre la construcción de sus subjetividades. Paralelamente, Vieira analiza los discursos y las prácticas de los agentes institucionales atendiendo a la dimensión moral que los atraviesa. Muestra una vez más cómo, cuando se trata de procesos que incluyen a adolescentes acusados de delitos, se advierte la constante oscilación entre la lógica punitiva (retar, castigar) y la tutelar (aconsejar, proteger, ayudar).

\section{Trayectorias interrogadas}

Este dossier concluye con una sección novedosa para la revista que busca reflexionar sobre los avatares, problemas y dilemas que atraviesan las prácticas cotidianas de antropólogos/as en su dimensión de reflexión y compromiso con los procesos sociales y políticos de los cuales son parte.

En esta ocasión, tenemos el gusto de presentar el trabajo de Javier Moro, quien, a través de recuerdos, anécdotas y notas de campo, nos propone una mirada retrospectiva del Estado y las políticas hacia la infancia en Argentina, entre mediados de los ochenta y principios de los noventa, en un contexto marcado por el regreso a la democracia y la aprobación de la CDN. A partir de su propia trayectoria, reflexiona sobre la construcción de la agenda pública en materia de infancia en la ciudad de Buenos Aires. Muestra cómo diversos activistas y profesionales implicados/as en la defensa y garantía de los derechos de los niños/as y adolescentes tuvieron un rol activo en la construcción de políticas y programas críticos a la perspectiva asistencialista y punitiva que por entonces caracterizaba la intervención con las infancias y adolescencias de sectores vulnerados. El recorrido escogido permite identificar transformaciones respecto de los problemas en torno a la infancia y de las respuestas dadas por el Estado, y muestra particularmente cómo la "niñez en calle" se instala como tema de agenda pública hacia fines de los ochenta.

El autor identifica el despliegue de diversas iniciativas impregnadas de nuevas miradas acerca del rol del Estado y de nuevas nociones de infancia promovidas por organizaciones no gubernamentales y recuperadas por el gobierno local con anterioridad a la sanción de la CDN. A partir de este este recorrido, contribuye a desarmar una mirada encantada del tratado internacional y discute la idea de modelos o paradigmas cerrados y sucedáneos en el tiempo. Al hacerlo, restituye el rol protagónico y las preocupaciones y anhelos de aquellos que participaron de la implementación de las mencionadas iniciativas y que luego, en los noventa, se apropiaron activa y creativamente del discurso de los derechos del niño. Muestra así que estas apropiaciones no ocurrieron en un vacío, sino en contextos históricos y políticos particulares.

\section{Palabras finales y nuevos desafíos para la investigación}

Los trabajos presentados en este dossier son reflejo de la expansión y el enriquecimiento que, durante los últimos años, han tenido los estudios sobre las intervenciones estatales destinadas a la protección y vigilancia de los niños/as y adolescentes. Sus análisis constituyen un valioso aporte al conocimiento de este campo de intervenciones, un campo que, sin lugar a dudas, se ha visto trastocado a partir de la pandemia de la COVID-19. Más allá de las diferentes etapas que la caracterizan, de la incertidumbre constante y del cambio permanente que este proceso aún abierto trae aparejado en los diferentes contextos locales, las diversas medidas sanitarias que debieron tomarse modificaron 
profundamente el trabajo cotidiano de las burocracias administrativas y judiciales. La necesidad de evitar el movimiento de personas y los contactos entre los agentes institucionales y entre estos y los destinatarios de sus intervenciones, sumada a la falta de espacios edilicios correctamente acondicionados para evitar los contagios, dio lugar a la emergencia de nuevas modalidades de trabajo en aquellas oficinas administrativas y judiciales acostumbradas a las interacciones cara a cara entre administradores y administrados.

Así, mientras algunos organismos combinaron modalidades de trabajo presencial y virtual, otros privilegiaron esta última forma, y cerraron sus puertas al público. $\mathrm{Si}$ bien la virtualidad generó en muchos casos intervenciones novedosas - por ejemplo, al agilizar los mecanismos de comunicación y denuncia de casos, digitalizar legajos y expedientes o facilitar encuentros entre profesionales de diferentes instituciones-, también puso en evidencia las falencias y dificultades de una institucionalidad conformada por organismos precarios, con escasos y deficientes recursos materiales y humanos. La pandemia también impactó sobre las instituciones destinadas tanto al cuidado de niños como a su encierro, dado que obligó a reducir el número de trabajadores/as abocados/as a tales tareas por ser personal de riesgo, e impidió a la vez los contactos entre el afuera y el adentro y, por ende, el ingreso de nuevos niños/as y adolescentes. Ante estas situaciones complejas y en un ámbito en el que los/as trabajadores/as reclaman históricamente mejores condiciones salariales, el latente malestar se acrecentó, lo que dio lugar a reclamos y conflictos laborales diversos.

Por otra parte, la pandemia afectó fuertemente las condiciones de vida de los niños/ as, adolescentes y sus familias que resultan destinatarios de este conjunto de acciones y dispositivos estatales. Los índices de pobreza alarman sobre su impacto en los sectores más desfavorecidos, y particularmente en esta franja de la población. Frente a este extraordinario contexto, resulta desafiante y necesario -hoy más que nunca- continuar documentando y analizando desde la perspectiva etnográfica las transformaciones en las modalidades de intervención y dinámicas de trabajo diarias de las burocracias administrativas y judiciales dedicadas a la protección y vigilancia de niños/as y adolescentes.

\section{Sobre las autoras}

María Florencia Graziano, doctora en Antropología (UBA), profesora adjunta del Departamento de Filosofía de la Facultad de Derecho (UNICEN), investigadora asistente del CONICET con sede en el Instituto de Ciencias Antropológicas e integrante del Equipo Burocracias, Derechos, Parentesco e Infancias, Programa de Antropología Política y Jurídica (ICA-FFyL-UBA).

Julieta Grinberg, doctora en Antropología Social y Etnología (EHESS, París), Profesora adjunta del Departamento de Ciencias Jurídicas y Sociales e investigadora del Instituto de Estudios Sociales en Contextos de Desigualdades (UNPAZ). Integrante del Equipo Burocracias, Derechos, Parentesco e Infancias, Programa de Antropología Política y Jurídica (ICA-FFyL-UBA). 


\section{Q Referencias bibliográficas}

"Abrams, P. (2006). Notes on the Difficulty of Studying the State. En A. Sharma y A. Gupta (Eds.), The Anthropoly of the State. A reader (pp. 112-131). Oxford: Blackwell Publishing.

» Barna, A. (2012). Convención Internacional de los Derechos del Niño. Hacia un abordaje desacralizador. Kairos, Revista de Temas Sociales, 16 (29), 1-19.

"Barna, A. (2015). La gestión de la infancia entre lo local y lo global. Una etnografía sobre intervenciones destinadas a 'restituir derechos de niños' en dispositivos estatales en las Leyes de Protección Integral (tesis de doctorado). Facultad de Filosofía y Letras, Universidad de Buenos Aires, Buenos Aires, Argentina.

"Ciordia, C. (2014). El tránsito institucional y la producción de niños adoptables: una etnografía de la gestión de la infancia y las familias (tesis de doctorado). Facultad de Filosofía y Letras, Universidad de Buenos Aires, Buenos Aires, Argentina.

" Ciordia, C. y Villalta, C. (2009). En búsqueda de la preservación del orden familiar: Medidas judiciales y administrativas vinculadas a la 'protección' de la niñez. En R. Kant de Lima, S. Tiscornia y L. Eilbaum (Orgs.). Burocracias penales, procesos institucionales de administración de conflictos y formas de construcción de ciudadanía: Experiencia comparada entre Brasil y Argentina (pp. 161-191). Buenos Aires: Antropofagia.

"Coutant, I. (2012). "C'est à vous de prendre votre destin en main." Les audiences pour mineurs en Maison de justice, une morale en actes. En D. Fassin y J-S. Eideliman (Dirs.). Economies morales contemporaines (pp.243-259). París: La Découverte.

»Das, V. y Poole, D. (2008). El Estado y sus márgenes: etnografías comparadas. Cuadernos de Antropología Social, 27, 19-52.

»Eilbaum, L. (2015). Familia, justicia y moralidades en el conurbano bonaerense. AntHropológicas, 22 (1), 7-35.

" Fassin, D. (2016). Una masacre de inocentes. Las representaciones de la infancia en tiempos de Sida. En D. Fassin. La razón humanitaria. Una historia moral del tiempo presente (pp. 235-263). Buenos Aires: Prometeo.

》Fonseca, C. y Cardarello, A. (2005). Derechos de los más y menos humanos. En S. Tiscornia y M. V. Pita (Eds.). Derechos humanos, tribunales y policías en Argentina y Brasil (pp. 9-42). Buenos Aires: Antropofagia.

» Foucault, M. (2007). La gubernamentalidad. En G. Giorgi y F. Rodríguez (Comps.). Ensayos sobre biopolítica: Excesos de vida (pp. 187-215). Buenos Aires: Paidós.

"Graziano, F. (2017). Pequeños juicios. Moralidades y derechos en la administración judicial para menores en la ciudad de Buenos Aires. Buenos Aires: Antropofagia.

»Graziano, F. (2020a). La mediación como una instancia de la justicia restaurativa: sentidos, interpretaciones y valoraciones. Cuestiones Criminales, 3 (5-6), 322-345.

" Graziano, F. (2020b). La justicia de menores en su dimensión cotidiana: los procesos de producción de micro decisiones. En E. Kostenwein (Dir.). El imperio de castigar. Contribuciones desde la sociología de la justicia penal (pp. 417-434). Editores del Sur:Buenos Aires.

" Grinberg, J. (2012). "Il y a un risque lorsqu'il y a un risque vital". Croisades morales et enjeux pratiques autour des négligences parentales dans la société argentine. En D. Fassin y J-S. Eideliman (Dirs.). Economies morales contemporaines (pp. 285-304). París: La Découverte. 
» Grinberg, J. (2013). La recepción de 'los derechos del niño’ en Argentina: trayectorias de activistas y conformación de una nueva causa en torno a la infancia. Revista de Antropología y Sociología Virajes, 15(1), 299-325.

»Grinberg, J. (2016). Los Suárez y las instituciones del sistema de protección de la infancia: Un análisis sobre las formas contemporáneas de gobierno de las familias en contextos de desigualdad y pobreza. Revista Latinoamericana de Ciencias Sociales, Niñez y Juventud, 14(1), 631-643.

» Grinberg, J. (2017). Prendre en charge la maltraitance infantile. Une ethnographie du traitement politique et moral de l'enfance en danger en Argentine (Tesis de doctorado). École des Hautes Études en Sciences Sociales, París, Francia.

»Llobet, V. (2009). Las políticas sociales para la infancia, la psicología y el problema del reconocimiento. Revista Investigaciones en Psicología, 14 (2), 73-94.

» Llobet, V. (2010). ¿Fábricas de niños? Las instituciones en la era de los derechos de la infancia. Buenos Aires: Noveduc.

» Lugones, M. G. (2012). Obrando en autos, obrando en vidas: Formas y fórmulas de protección judicial en los Tribunales Prevencionales de Menores de Córdoba, Argentina, a comienzos del siglo XXI. Río de Janeiro: E-papers.

» Magistris, G. (2016). El gobierno de la infancia en la era de los derechos. Prácticas locales de "protección y restitución de derechos de Niños, Niñas y Adolescentes" en dos municipios del conurbano bonaerense (tesis de doctorado). Facultad de Ciencias Sociales, Universidad de Buenos Aires, Buenos Aires, Argentina.

» Medan, M. (2017). Prevención social y delito juvenil. Buenos Aires: TesoPress.

" Medina, F. (2019). Recorridos frecuentes. Una etnografía en el campo penal juvenil de Santiago del Estero, Argentina (tesis de doctorado). Facultad de Filosofía y Letras, Universidad Nacional de Tucumán, Tucumán, Argentina.

» Merry, S. E. (2006). Transnational Human Rights and Local Activism: Mapping the Middle. American Anthropologist, 108(1), 38-51.

» Merry, S. E. (2009). Vernacularization in Action: Using Global Women's Human Rights Locally. Special Issue of Global Networks 9(4), 441-461.

»Rojas Novoa, S. (2017). La protección de la infancia en América: una problematización histórica del presente. El caso del Instituto Interamericano del Niño, la Niña y Adolescentes (19161989) (tesis de doctorado). Laboratoire du Changement Social et Politique, Universidad París VII, París, Francia y Facultad de Filosofía y Letras, Universidad de Buenos Aires, Buenos Aires, Argentina.

»Santillán, L. (2013). Entre la ayuda y el “desligamiento": prácticas y regulaciones cotidianas sobre las familias y el cuidado infantil en barrios populares del Gran Buenos Aires. Civitas, 13(2), 316-335.

»Sharma, A. y Gupta, A. (Eds.) (2006). Introduction: Rethinking Theories of the State in an Age of Globalization. En The Anthropoly of the State. A reader (pp. 1-43). Oxford: Blackwell Publishing.

» Trouillot, M. R. (2001). The anthropology of the state in the age of globalization. Close encounters of the deceptive kind. Current anthropology, 42(1), 125-138.

»Vianna, A. (Comp.) (2010). Derechos, moralidades y desigualdades: Consideraciones a partir de procesos de guarda de niños. En Infancia, justicia y derechos humanos (pp. 21-72). Bernal: Editorial de la Universidad Nacional de Quilmes [Colección Derechos Humanos]. 
»Villalta, C. (2010). La administración de la infancia en debate. Entre tensiones y reconfiguraciones institucionales. Estudios de Antropología Social, 1(2), 81-99.

»Villalta, C. (2013). Un campo de investigación: las técnicas de gestión y los dispositivos jurídico-burocráticos destinados a la infancia pobre en la Argentina. Civitas, 13(2), 245268.

»Villalta, C. (2019). La Convención sobre los Derechos del Niño en perspectiva. Temporalidades, disputas y desafíos en el proceso de construcción de los sistemas de protección integral de derechos de niños, niñas y adolescentes en la Argentina. En M. Herrera, A. Gil Domínguez y L. Giosa (Dirs.). A treinta años de la Convención sobre los Derechos del Niño. Avances, críticas y desafíos (pp. 65-86). Buenos Aires: EDIAR. 
